Copyright by the AIP Publishing. Liu, YJ; Wang, AB; Claus, RO, "Layer-by-layer electrostatic self-assembly of nanoscale Fe304 particles and polyimide precursor on silicon and silica surfaces," Appl. Phys. Lett. 71, 2265 (1997); http:// dx.doi.org/10.1063/1.120046

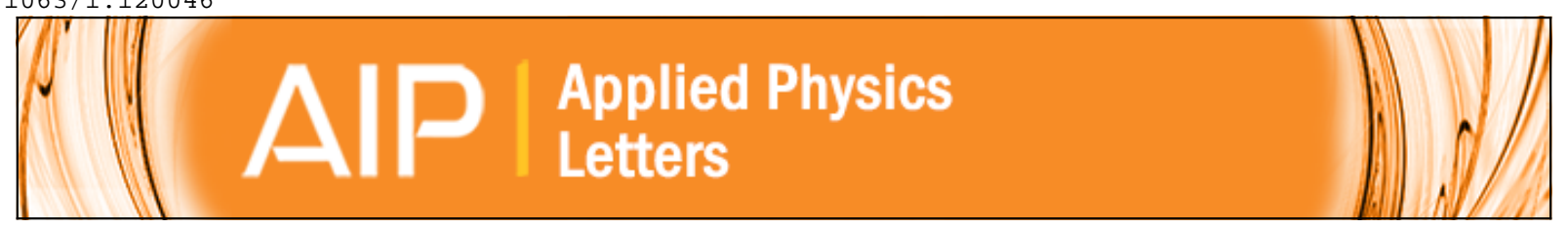

\title{
Layer-by-layer electrostatic self-assembly of nanoscale Fe 304 particles and polyimide precursor on silicon and silica surfaces
}

Yanjing Liu, Anbo Wang, and Richard O. Claus

Citation: Applied Physics Letters 71, 2265 (1997); doi: 10.1063/1.120046

View online: http://dx.doi.org/10.1063/1.120046

View Table of Contents: http://scitation.aip.org/content/aip/journal/apl/71/16?ver=pdfcov

Published by the AIP Publishing

\section{Articles you may be interested in}

Area-selective deposition of self-assembled monolayers on Si O $2 \mathrm{Si} \mathrm{(} 100$ ) patterns

Appl. Phys. Lett. 89, 233105 (2006); 10.1063/1.2400114

Crystallite size dependence of natural resonance frequency for spin-sprayed Fe $3 \mathrm{O} 4-\mathrm{Fe} 2 \mathrm{O} 3$ films highly permeable up to gigahertz range

J. Appl. Phys. 97, 10G109 (2005); 10.1063/1.1862096

Amino-terminated self-assembled monolayer on a SiO 2 surface formed by chemical vapor deposition

J. Vac. Sci. Technol. A 19, 1812 (2001); 10.1116/1.1336833

Formation of alkylsiloxane self-assembled monolayers on Si $3 \mathrm{~N} 4$

J. Vac. Sci. Technol. A 17, 540 (1999); 10.1116/1.581616

Study of the magnetic and magneto-optical properties of [110]-oriented $\mathrm{Fe} 3 \mathrm{O} 4$ / NiO superlattices

J. Appl. Phys. 81, 5010 (1997); 10.1063/1.364489

\section{AlP Re-register for Table of Content Alerts}

\section{Create a profile. \\ Sign up today!}

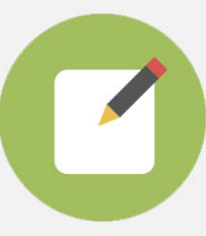




\title{
Layer-by-layer electrostatic self-assembly of nanoscale $\mathrm{Fe}_{3} \mathrm{O}_{4}$ particles and polyimide precursor on silicon and silica surfaces
}

\author{
Yanjing Liu, Anbo Wang, and Richard O. Claus \\ Bradley Department of Electrical Engineering, Fiber and Electro-Optics Research Center, Virginia \\ Polytechnic Institute and State University, Blacksburg, Virginia 24061-0356
}

(Received 17 March 1997; accepted for publication 22 August 1997)

\begin{abstract}
Monolayer and multilayer ultrathin films comprised of nanosized iron oxide $\left(\mathrm{Fe}_{3} \mathrm{O}_{4}\right)$ particles and polyimide molecules have been fabricated on single crystal silicon and quartz substrates by a novel layer-by-layer electrostatic self-assembly process. This process involves the alternate dipping of a substrate into an aqueous solution of anionic polyimide precursor (polyamic acid salt, PAATEA), followed by dipping into an aqueous solution of polycation polydiallyldimethylammonium chloride (PDDA) which coats on nanoscale $\mathrm{Fe}_{3} \mathrm{O}_{4}$ particles as a stabilizer. The growth process and the structure have been characterized using UV-vis spectroscopy, contact angle, and ellipsometry measurements. The results suggest that well-ordered uniform monolayer and multilayer magnetic films have been formed on silicon and silica surfaces. A recently developed highly sensitive fiber optic magnetic field sensor was used to probe the small magnetic field intensity produced by the multilayer films. (C) 1997 American Institute of Physics. [S0003-6951(97)03842-4]
\end{abstract}

Magnetic nanoparticles and ultrathin films have attracted interest from both experimental and theoretical points of view ${ }^{1}$ because of their potential applications in information storage, ${ }^{2}$ magnetic imaging, ${ }^{3}$ ferrofluids, ${ }^{4}$ and magnetic separation. ${ }^{5}$ Several different techniques for the construction of thin magnetic films have been reported, including sputtering, ${ }^{6}$ vapor trapping, ${ }^{7}$ carbon arc formation, ${ }^{8}$ and molecular beam epitaxy (MBE). ${ }^{8}$ However, there are inherent limitations associated with these methods including very expensive fabrication equipment, limited film area or thickness, high temperature processing, costly fabrication, and complex and time-consuming processing.

Here we report a new method for the preparation of monolayer and multilayer magnetic $\mathrm{Fe}_{3} \mathrm{O}_{4}$ /polyimide films by a novel molecular self-assembly process. Several steps are involved in our approach. First, nanoscale magnetite particles $\left(\mathrm{Fe}_{3} \mathrm{O}_{4}\right)$ were synthesized, according to a method described elsewhere. 9 A mixed aqueous solution of ferric chloride and ferrous chloride was poured into ammonium solution. The instantaneously formed black precipitate was separated by centrifugation without washing with water. Then, the precipitate was redissolved and ultrasonically agitated in an aqueous solution of poly(diallyldimethylammonium chloide) (PDDA) at a $\mathrm{pH}$ of 8.5. The coagulation and precipitation of these particles were prevented by the adsorption of cationic polyelectrolyte (PDDA). The resulting darkbrown $\mathrm{Fe}_{3} \mathrm{O}_{4}$ solution is stable over a period of months and is sensitive to the $\mathrm{pH}$ values of the water solution. The typical size of the PDDA-coated magnetite particles is about 10 $\mathrm{nm}$, as demonstrated by transmission electron microscopy (TEM) in Fig. 1.

It is commonly known that any study of nanosized particles must insure against surface oxidation. This is particularly a problem for iron-based materials, because surface oxidation can cause a reduction in total magnetization. ${ }^{10}$ On the other hand, polyimides have an excellent combination of thermal stability, chemical resistivity, very high mechanical strength even at high temperature, low thermal expansion coefficient and dielectric constant, and extremely low moisture uptake, so may serve as good candidates for the protection of formed iron oxide layers. Therefore, a thermoplastic polyimide precursor polyamic acid salt (PAATEA) of Ultem $^{\mathrm{TM}}$ with controlled molecular weight $(\mathrm{Mw}=30000 \mathrm{~g} /$ mole, after the imidization ${ }^{11}$ ) was obtained and used as anionic polyelectrolyte inserted as a protective layer between alternating iron oxide particle layers.

Third, the fabrication of $\left(\mathrm{PDDA}: \mathrm{Fe}_{3} \mathrm{O}_{4}\right) / \mathrm{PAATEA}$ monolayer and multilayer films was carried out as follows.

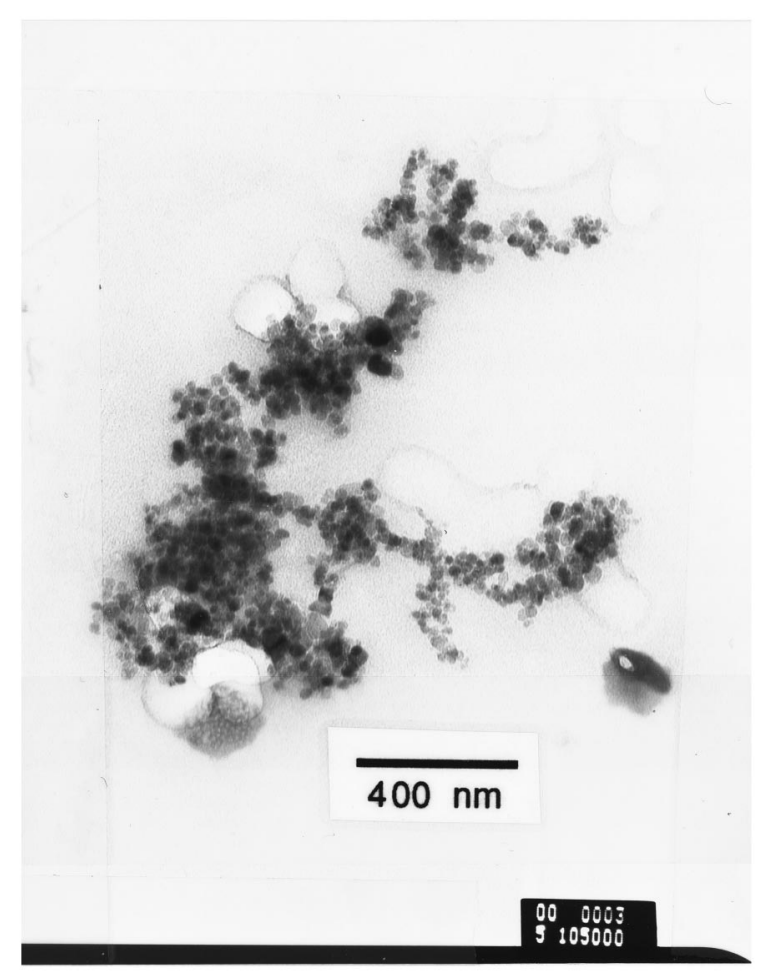

FIG. 1. Transmission electron micrograph of average $10 \mathrm{~nm}$ diameter iron oxide particles coated with PDDA in the aqueous dispersion. 

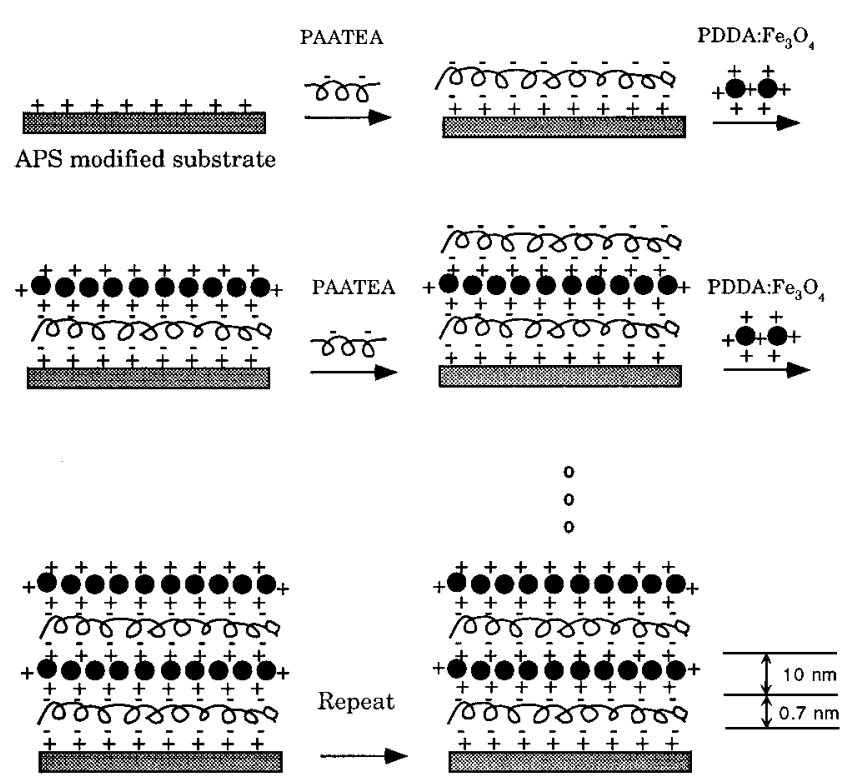

FIG. 2. Schematic illustration of the formation of multilayer ultrathin magnetic films by electrostatic molecular self-assembly process.

The substrates used were single crystal silicon p-111, quartz, and optical glass. Well cleaned slides were immersed in a $1 \%$ volume solution of ( $N$-2-aminoethyl-3-aminopropyl) trimethoxysilane (APS, 94\%, Huls America, Inc.) in toluene for two hours at a temperature of $46^{\circ} \mathrm{C}$. After silanization, the slides were ultrasonically agitated for two minutes each in pure toluene, a toluene/methanol (1:1) mixture twice, and pure methanol twice, then thoroughly rinsed with ultrapure water. Thus a monolayer of APS with amine functionalities was covalently anchored onto the substrate which was to be protonated, and a positively charged surface was provided in the proper $\mathrm{pH}$ ranges. The slide was then immersed in a $1 \%$ $(\mathrm{w} / \mathrm{w})$ aqueous solution of PAATEA with a $\mathrm{pH}$ of 8.5 for 10 min, then rinsed extensively with ultrapure water and blown dry with nitrogen gas. Subsequently, the slide was dipped into the cationic solution of $\left(\mathrm{Fe}_{3} \mathrm{O}_{4}: \mathrm{PDDA}\right) / \mathrm{H}_{2} \mathrm{O}(3 / 1.5 / 50$, $\mathrm{w} / \mathrm{w}$ ) with a $\mathrm{pH}$ of 8.5 for $10 \mathrm{~min}$, followed by thorough washing with water and drying with nitrogen gas. By repetition of this simple two-step process in a cyclic fashion, alternating layer-by-layer molecular self-assembly of one layer of PAATEA and one layer of PDDA: $\mathrm{Fe}_{3} \mathrm{O}_{4}$ nanoparticles into multilayer films was obtained, and in principle, there is no limit for the final thickness.

The spontaneous, layer-by-layer self-assembly of the cationic PDDA: $\mathrm{Fe}_{3} \mathrm{O}_{4}$ nanoparticles between the anionic polyamic acid salt (PAATEA) layers is based on the ionic attraction developed between the oppositely charged species, which promotes strong interlayer adhesion and a uniform and linear multilayer deposition process. ${ }^{12}$ The key to a regular multilayer buildup is the reversal of the surface charge in each adsorbed layer, as shown in Fig. 2. Since iron oxide nanoparticles in a dispersion will rapidly aggregate if not provided with a potential energy barrier to prevent it, the cationic polyelectrolyte PDDA is used as a stabilizer to anchor on the particle surfaces and guarantee the requisite positive charge on the particles. On the other hand, the stability of the anionic polyamic acid salt (PAATEA) is dependent on

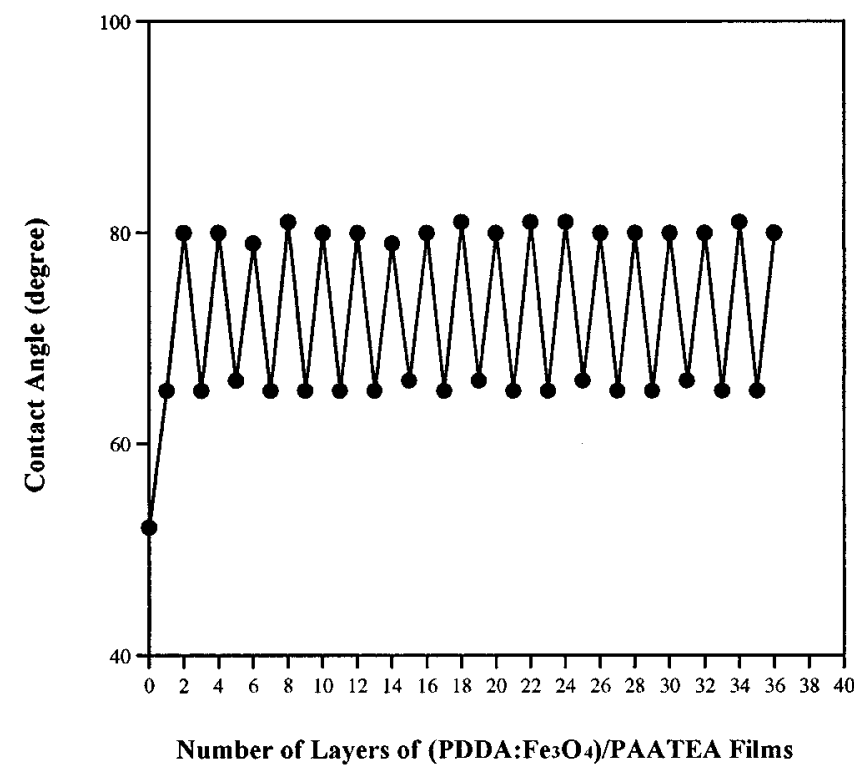

FIG. 3. Contact angle on the surface of $\left(\mathrm{PDDA}: \mathrm{Fe}_{3} \mathrm{O}_{4}\right) / \mathrm{PAATEA}$ multilayer films as a function of number of layers.

the $\mathrm{pH}$ values and temperature. Therefore, the processing variables must be adjusted to ensure the optimal conditions for the construction of monolayer and multilayer films based on the electrostatic self-assembly process. The thickness of bilayer of (PDDA: $\mathrm{Fe}_{3} \mathrm{O}_{4}$ )/PAATEA is determined to be 11 $\mathrm{nm}$ by ellipsometry measurements.

A contact angle goniometer was used to probe the growth of the alternating multilayer structures. Whitesides et al. and others have shown, qualitatively, the wettability of a solid is determined by the structure of its outermost few angstroms, ${ }^{13}$ so one would expect that the contact angle should vary if a solid is modified by an electrostatic multilayer film. Water contact angles measured for the outermost surface of the (PDDA: $\mathrm{Fe}_{3} \mathrm{O}_{4}$ )/PAATEA multilayer films with increasing number of layers from 1 to 36 (18 bilayers) are shown in Fig. 3. For an APS modified silicon or silica surface, the water contact angle is $52^{\circ}$. After one layer of anionic polyamic acid salt (PAATEA) is adsorbed on the surface, the water contact angle is increased to $65^{\circ}$. Then, the contact angle rises to $80^{\circ}$ when cationic PDDA modified particles are deposited on the surface (the higher the water contact angle, the more hydrophobic the surface). It can be seen that the average water contact angle oscillates according to which molecules form the outermost layer (PDDA: $\mathrm{Fe}_{3} \mathrm{O}_{4}$ ) and PAATEA, and remains about the same after 36 layers (18 bilayers) are deposited onto the positively charged surface (APS modified silicon surface). This clearly demonstrates that the consecutive adsorption of anionic PAATEA and cationic PDDA: $\mathrm{Fe}_{3} \mathrm{O}_{4}$ is stepwise and the deposition process is very consistent from layer to layer and highly reproducible.

Optical UV-vis spectroscopy was also used to characterize the growth of the multilayer structures and the amount of material deposited per layer. Optical absorbance spectra following the deposition process and growth of (PDDA: $\mathrm{Fe}_{3} \mathrm{O}_{4}$ )/PAATEA multilayer films on a modified quartz slide are shown in Fig. 4. By UV-vis spectroscopy a linear deposition pattern of 17 bilayers film is observed with 


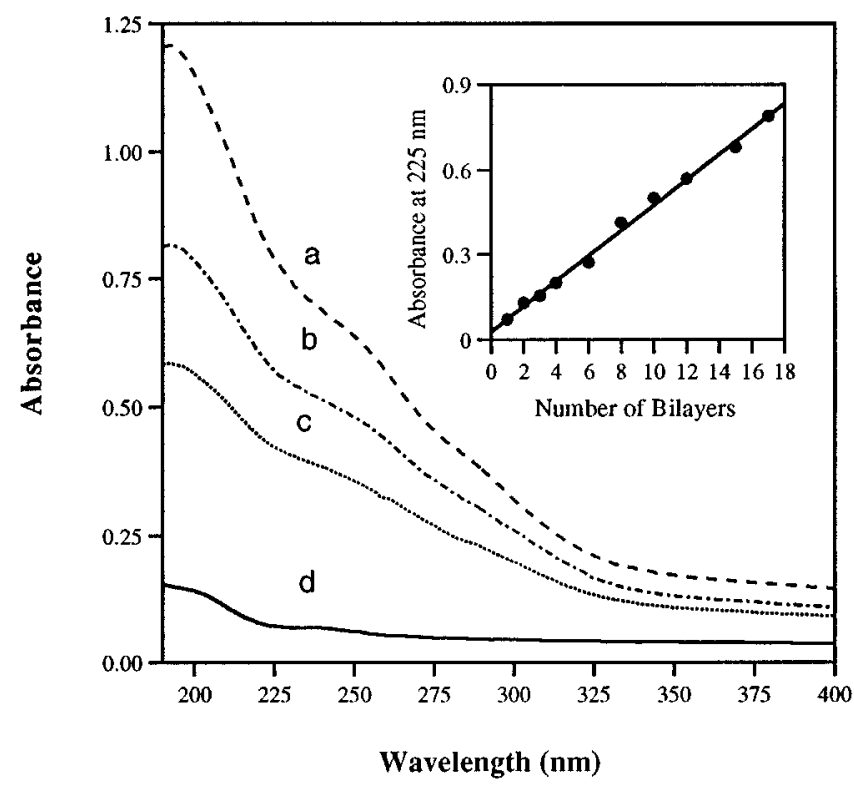

FIG. 4. Optical absorbance spectra of (PDDA: $\left.\mathrm{Fe}_{3} \mathrm{O}_{4}\right) / \mathrm{PAATEA}$ multilayer films [(a) 17 bilayers; (b) 12 bilayers; (c) 8 bilayers; and (d) 1 bilayer] with inset showing the linear relationship between absorbance at $225 \mathrm{~nm}$ and number of bilayers deposited.

respect to the number of bilayers of films, yielding an average optical density of $0.045 \pm 0.030$ (at $225 \mathrm{~nm}$ ) per bilayer. The linear nature of the plot suggests that each layer adsorbed contributes an equal amount of material to the thin film.

Methods for measuring very small magnetic fields typically involve use of superconducting quantum interference devices (SQUID), which are very expensive and require supercooling. Recently, a fiber optic magnetic sensor with a sensitivity of 100 nanotesla has been developed in our laboratory ${ }^{14}$ and we used it to evaluate the magnetic flux density of the fabricated thin-films. The distance between the specimen plane and the sensor was $2 \mathrm{~cm}$. Samples having 2, 4,8 , and 16 bilayers were studied, the corresponding values of the magnetic flux density perpendicular to the film plane were 2000, 4000, 6000, and $12000 \mathrm{nT}$. This yielded an average magnetic flux density per bilayer of $850 \mathrm{nT}$ at a distance of $2 \mathrm{~cm}$. One would expect that a sharp increase in magnetic field intensity would be obtained as the film plane approaches the sensor. Further detailed magnetic measurements are in progress.

These preliminary results indicate that an electrostatic molecular self-assembly process can be used to construct monolayer and multilayer magnetic films in which a high performance and moisture-adsorption free polyimide is sandwiched. One of the advantages of this technique is that the thickness of each layer can be varied at Ångström level, so the electrical resistance can be varied at very high precision which will be very promising for the fabrication of giant magnetoresistance (GMR) devices. In future work, we hope to demonstrate that this new process of magnetic film formation can be carried out with several quite different functional materials such as conjugated polymers, and nanosized metals. This remarkably simple technique provides molecularlevel control over the thickness and complicated architecture of multilayer magnetic, conducting, ${ }^{15}$ and luminescent films. ${ }^{16}$ Thus it offers a potentially powerful strategy for fabricating nanomagnetic, nanoelectronic-magnetic, nanomagnetic-optical, and nanomagnetic-electroluminescent devices.

The authors would like to thank Professor R. Davis for a gift of PAATEA solutions and are indebted to K. D. Oh and $\mathrm{J}$ Ranade for the measurement of magnetic flux density.

${ }^{1}$ E. Bonetti and D. Fiorani (Editors), Nanophase Materials (Trans Tech, 1995); A. Hernando (Editor), Nanomagnetism (Kluwer-Academic, New York, 1993); R. F. Ziolo, E. P. Giannelis, B. A. Weinstein, M. P. O'Horo, B. N. Ganguly, V. Mehrotra, M. W. Russel, and D. R. Huffman, Science 257, 219 (1992).

${ }^{2}$ R. G. L. Audran and A. P. Huguenard, U.S. Patent No. 4,302,523 (1981); H. N. Bertram, Theory of Magnetic Recording (Cambridge University Press, Cambridge, 1994); M. H. Kryder, in Applied Magnetism, edited by R. Gerber, C. D. Wright, and G. Asti (Kluwer-Academic, New York, 1993), Vol. 253, p. 39.

${ }^{3}$ Q. A. Pankhurst and R. J. Pollard, J. Phys.: Condens. Matter 5, 8487 (1993).

${ }^{4}$ A. I. Anton, J. Magn. Magn. Mater. 85, 137 (1990).

${ }^{5}$ R. Gerber, in Applied Magnetism, edited by R. Gerber, C. D. Wright, and G. Asti (Kluwer-Academic, New York, 1993), Vol. 253, p. 165.

${ }^{6}$ L. M. Falicov, D. T. Pierce, S. D. Bader, R. Gronsky, K. B. Hathaway, H. J. Hopster, D. N. Lambeth, S. S. P. Parkin, G. Prinz, M. Salamon, I. K. Schuller, and R. H. Victora, J. Mater. Res. 5, 1299 (1990).

${ }^{7}$ G. N. Glavee, K. Eason, K. J. Klabunde, C. M. Sorensen, and G. C. Hadjipanayis, Chem. Mater. 4, 1360 (1992).

${ }^{8}$ J. J. Rhyne, R. W. Erwin, J. A. Borchers, M. B. Salamon, F. Tsui, R. Du, and C. P. Flynn, in Sci. and Tech. of Nanostructured Magnetic Materials, edited by G. C. Hadjipanayis and G. A. Prinz (Plenum, New York, 1991), p. 117.

${ }^{9}$ R. Massart, IEEE Trans. Magn. 17, 1247 (1981).

${ }^{10}$ G. C. Hadjipanayis, S. Gangopadhyay, C. M. Sorensen, and K. J. Klabunde, IEEE Trans. Magn. 29, 2602 (1993).

${ }^{11}$ R. Davis, Department of Chemical Engineering, Virginia Tech (private communication).

${ }^{12}$ G. Decher, J. D. Hong, and J. Schmitt, Thin Solid Films 210/211, 831 (1992); Y. Liu, A. Wang, and R. O. Claus, J. Phys. Chem. B 101, 1385 (1997).

${ }^{13}$ E. B. Troughton, C. D. Bain, G. M. Whitesides, R. G. Nuzzo, D. L. Allara, and M. D. Porter, Langmuir 4, 365 (1988); C. D. Bain and G. M. Whitesides, Science 240, 62 (1988).

${ }^{14}$ K. D. Oh, J. Ranade, V. Arya, A. Wang, and R. O. Claus, IEEE Photonics Tech. Lett. (to be published).

${ }^{15}$ M. Ferreira and M. F. Rubner, Macromolecules 28, 7101 (1995).

${ }^{16}$ H. P. Hong, D. Davidov, Y. Avny, H. Jchayet, E. Z. Faraggi, and R. Neumann, Adv. Mater. 7, 846 (1995). 